\title{
On some uses and abuses of topology in the social analysis of technology (Or the problem with smart meters)
}

Noortje Marres (Goldsmiths), March 2012, submitted to Theory, Culture and Society

\begin{abstract}
This article examines different ways in which topological ideas can be used to analyse technology in social terms, arguing that we must become more discerning and demanding as to the limits and possibilities of topological analysis than used to be necessary. Topological framings of technology and society are increasingly widespread, and in this context, it becomes necessary to consider topology not just as a theory to be adopted, but equally as a device that is deployed in social life in a variety of ways. Digital technologies require special attention in this regard: on the one hand, these technologies have made it possible for a topological imagination of technology and society to become more widely adopted; on the other hand, they have also enabled a weak form of topological imagination to proliferate, one that leaves in place old, deterministic ideas about technology as a principal driver of social change. Turning to an empirical case, that of smart electricity metering, the article investigates how topological approaches enable both limited and rigorous 'expansions of the frame' on technology. In some cases, topology is used to imagine technology as a dynamic, heterogeneous arrangement, but 'the primacy of technology' is maintained. In other cases a topological approach is used to bring into view much more complex relations between technological and societal change. The article ends with an exploration of the topological devices that are today deployed to render relations between technological and social change more complexly, such as the online visualisation tool of tag clouding. I propose that such a topological device enables an empirical mode of critique: here, topology does not just help to make the point of the mutual entanglement of the social and the technical, but helps to dramatize the contingent, dynamic and non-coherent unfolding of issues
\end{abstract}

\section{Introduction}

It is hard to overestimate the importance of topology, loosely defined, to the development of social studies of technology in recent decades. Topological ideas 
have been a significant source of inspiration for several different approaches, and can be recognized in the idea of the inter-relatedness of technology and society. These approaches have done much to help dismantle the idea that technology and society occupy different domains. Thus, now classic contributions to the social studies of technology have proposed the concept of a hybrid network, or heterogeneous 'assemblage', which is variously composed of social, technical and natural entities, as our best chance at understanding the role of technology in social life (Callon, Law and Rip, 1986; Latour, 1988; Haraway, 1994). These studies reference uses of topology in the sciences, from mathematics to theoretical physics, in particular the analytic category of 'entities-in-relation', proposing that social studies of technology should follow these other fields: they too should adopt this topological notion as their primary category of analysis.

But something seems to have changed, which requires us to re-consider the use of this central concept in the social analysis of technology. Over the last ten years or so, the use of topological ideas to conceive of technology in relational terms has become increasingly widespread. These ideas can be recognized in the proliferation of network visualisations, in digital networked media, and the invocation of the concepts of complexity in a broad array of settings (see on this point also Boltanksi and Chiapello, 2005). Today, then, it is not just social students of technology who deploy topological ideas in order to render technology analysable, but a whole range of social agents. This entails a change of status of topology in the social analysis of technology. In the social studies of technology, topology has been mostly understood as a theoretical construct, as a conceptual language that can help social theory to render explicit the structure of socio-technical phenomena. However, at the current juncture, topology must also be understood as a device, as a way of structuring phenomena in practice, which is enabled (and disabled) by particular technologies. We must, 
then, attend more closely to how a topological imagination is enabled by specific material apparatuses deployed across social life.

Crucially, to approach topology as an imaginary means to adopt a fairly minimal definition of it in a mathematical sense, as the important question becomes that of how a topological imagination of technology and society arises and takes form in material practice. The issue becomes that of the empirical specification of a topological imaginary of technology and society; to consider that it may be deployed in a range of different ways. One of the striking facts about the recent spread of topological approaches to technology and society, I argue, is how often it does not translate into the kinds of insights for which sociologists of technology have appreciated these approaches in the past. In the social studies of technology, topological ideas were principally taken up in order to challenge a particular dominant ideal concerning the role of technology in society, which we can call the "primacy of technology". However, while topology is today frequently used to analyse and organise technology in social terms, this often leaves undisturbed the understanding of technology as the principal 'driver' of social change.

In this context, it becomes especially important for social analysts to distinguish between seemingly similar ways of using topological approaches in the social analysis and organisation of technology. Rather than dramatizing the opposition between pre-topological and topological understandings of society and technology - and making the case for the latter over against the former - we must attend to more subtle differences between a range of topological analyses of this relation, in particular between those that do and those that do not problematize the primacy of technology. We must distinguish between 'weak' and 'strong' versions of the topologization of technology and society, and become more demanding of how topology is deployed in practice. 
To this end, I will here turn to an empirical field in which topology has been deployed with special intensity in recent years, that of smart meter technology. This technology has captured the imagination of engineers, designers, sociologists, policy makers, and advertisers alike, and, as such, it has enabled a variety of different topological analyses of technology and society in a range of fields, with a range of different implications for our understanding of the relation between the social and the technical. As such, it provides a useful object for demonstrating the differences between a limited and a more radical topologization of the social and the technical. To clarify this difference, I will turn to the phenomenon of the "issuefication" of smart meters. But let us begin by considering the use of topology as a device.

\section{Expanding the frame? The neat complexities of smart electricity meters}

Energy technology is certainly not the only site, but it is an especially prominent one in which topological ideas are being invoked in order to envision relations between social and technological change. Devices from wind turbines to solar panels are today granted special significance as examples of how we could 'manage' in a turbulent world; they have become powerful instances of the project to bring social, technological and environmental change into alignment with one another. Importantly, digital technology tends to figure in a privileged role, as what enables this convergence of different forms of change. Here is a rather enchanted version of this general idea as it figures in a recent IBM advertisement:

Fortunately our energy can be made smart. It can be managed like the global complex system that it is. We can now instrument everything from the meter in the home to the turbines in the plants to the network itself. [...] All of this instrumentation generates new data, which advanced analytics 
can turn into insight, so that better decisions can be made in real time. Decisions by individuals and business on how they can consume more efficiently. Decisions by utility companies on how they can better manage delivery and balance loads. Decisions by governments and societies on how to preserve the environment. ${ }^{1}$

Advertisements like these make various connections between technology, society, and nature by evoking a classic trope drawn from cybernetics, that of the complex system (Nye, 1999; De Landa, 1991; Edwards, 2000). In referring to 'complex systems,' such publicity material invokes a 'topological imaginary': it highlights a) the dynamic nature of technical and social arrangements and b) the interrelatedness of different levels or orders, in this case technology, society and the environment.

In invoking such ideas, promotional accounts of technology call to mind classic ideas from the sociology of technology. Sociologists have long insisted on the entanglement of technology and society, with some arguing that if we want to properly appreciate their mutual imbrication, we must adopt a 'dynamic ontology' or indeed, a 'topological imagination.' This argument is generally associated with social studies of technology of recent decades, but it is worth pointing out that classic social theorists, too, deployed proto-topological ideas in order to dissolve the separation between the technical and the social. Thus, the post-pragmatist social theorist Alfred Schutz proposed that social reality in technological societies is organised through changing 'topographies' of relevance (Schutz, 1964; see also Schutz, 1970). In his account, everyday subjects and experts do not inhabit different orders of social and technical knowledge, but each access different 'regions' of social and technical knowledge depending on

\footnotetext{
1 "Smarter energy for a smarter planet", IBM Ad, Financial Times, special issue on the future of energy, November 4, 2009. See also http://www.ibm.com/smarterplanet/us/en/smart_grid/visions/index.html
} 
their tasks at hand, and these regions themselves are constantly changing as an consequence of the emergence of new technologies and forms of expertise.

In the 1980s and 1990s, sociologists of technology began importing topological ideas into their field. Authors associated with actor-network theory (ANT), such as Latour (1993) Callon (1986), and Mol and Law (1994), and feminist scholars of technology like Haraway (1994) and Suchman (2005), coined concepts like the 'heterogeneous network' and the 'socio-technical assemblage'. These concepts highlight that social and technical entities in practice are always already entangled, not just on the level of our knowledge about the world (as Schutz had demonstrated), but materially or 'ontologically' speaking. The concept was especially elaborated in actor-network theory, which sought to sabotage a debate then existing in social theory, about whether the social shapes the technical or the other way around. If social and technical entities are in practice always encountered as entangled in heterogeneous formations, as ANT and feminist scholars proposed, then a strict separation between the social and the technical, and hence this question about what shapes what, makes no sense (Haraway, 1994; see also Leigh Star, 1991).

In developing these perspectives, these social analysts of technology drew inspiration from early $20^{\text {th }}$ century physics, and relativity theory in particular, where topological ideas had found an influential application, as in the idea that 'objects-in-relation' generate their own space-times (Latour, 1988; Callon et al, 1986). In theoretical physics, these ideas had helped turn space and time from 'a priori' into 'a posteriori' categories, and, in an indirect way, this enabled the reformulation of the theoretical question of the relation between the social and the technical. It made it possible to suspend the tacit habit of sociological theory to model social space on classic 'Euclidean' space, with its familiar geometry of stable, singular entities positioned against the external 
backdrop of a static space and linear time. The rejection of this geometry dissolved an engrained conceptual pattern of the debate about society 'versus' technology: that debate demanded a decision a priori, on theoretical grounds, as to whether we should think of technology as invading social space, or vice versa. In positing the heterogeneous or 'socio-technical' network as the primary category of analysis, each configuration of elements could now be said to generate its own distinct space-time, with its particular scales, extension and rhythm, emerging from the changing relations among a diverse set of entities (Latour, 1993; Michael, 2000; Mol and Law, 1994). This conceptual move did not only dissolve the issue of the analytic priority of the social or the technical, it also directed attention away from the relation between technology and society, and towards dynamics that are internal to socio-technical formations.

The adoption of a topological imaginary is thus crucial to understanding both the conceptual interventions and normative commitments of the social studies of technology, and especially actor-network theory. But at the same time, these interventions and commitments cannot be understood as the results, in and of themselves, of a topological imagination. This is becoming clear today, as a whole range of actors invoke topological ideas in order to analyse technology in social terms, but do not share the commitments of ANT and feminist STS. Arguably, then, a topological understanding of technology and society is today no longer purely an issue of sociological theory: the propagation of such an imaginary now presents a much more widely shared societal project, and indeed an operation enabled by technology itself.

A recent lead article in a popular science and technology magazine called SEED, on 'how social science can help solve climate change', provides a case in point. The piece begins by acknowledging the complexity of the social, stating that "human beings' decision-making processes are probably as complicated as the 
climate system itself', proposing that the contribution of social science is critical to "solving the environmental crisis." ${ }^{2}$ In envisioning a future role for a social science of complexity, technology is singled out as crucial. According to this article (and many others) the new social science of complexity will prove its worth by informing the design of environmental awareness technologies and "other devices to help funnel us into more pro-environmental behaviour." In this respect, it may be useful or even necessary for us, who are involved the social analysis of technology today, to approach the topological imagination of technology and society not as a theoretical construct, but as a device.

\footnotetext{
${ }^{2}$ David Zax, The Last Experiment, SEED Magazine, April 22, 2009, $\mathrm{http} / /$ seedmagazine.com/content/article/the_last_experiment/ The article offers a particular translation of the environmental crisis into a proposition of social science, one that turns this crisis into a behavioural problem: "We know the climate demands action. We know all these things and yet we do not act. Why: we don't exactly know. And that makes climate change a question for social scientists like Ben Ho."
} 

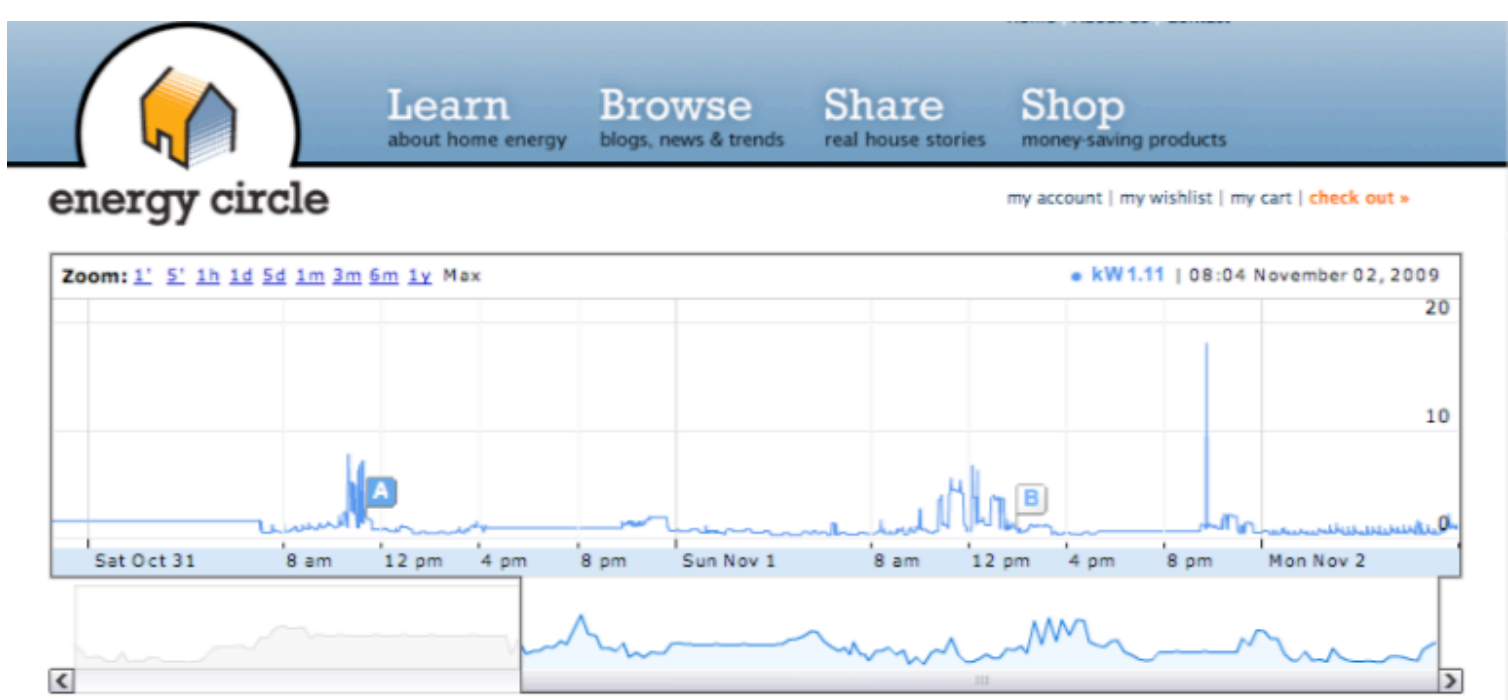

Friday night

$8 \mathrm{pm}$. Doesn't that look fun? Not telling. $14.9 \mathrm{kWh}$ today / $0.92 \mathrm{~kW}$ now Well

Really just want to blame it on the teenagers. $17.2 \mathrm{kWh}$ today / $1.79 \mathrm{~kW}$ now

\section{What is this?}

We have long argued that energy efficiency begins with measuring. In honor of Earth Day, and to demonstrate our commitment to the overwhelming significance of home energy efficiency in reducing carbon emissions, we are not only measuring our usage, but laying bare the way our house uses electricity, right here. And on Twitter e. EnergyCircleKW.

\section{How does it work?}

This chart is a live feed of our family's energy consumption. We have wired our household electricity monitor (T.E.D. The Energy Detective) to display our actual energy out-put direetly to this site, and to stream to Twitter. Click on a time increment to find out which of our mundane daily tasks caused our energy use to peak, or dive. You won't be able to see us wash our laundry, but you'll notice a shift in wattage when we do it. Our energy

Figure 1: The Energy Detective

As is clear from the above, in the social studies of technology topology has been used to make a highly abstract intervention in social theory, as it provided inspiration for an alternative conception of the relation between society and technology. But a topological imaginary is today deployed in a much more concrete way to conceive of technology in social terms. In the current context, digital devices themselves invoke topological ideas in order to bring the social and the technological together. To elaborate this point through another example, the Energy Detective is a Web-based application designed to showcase the opportunities opened up by smart electricity meters for generating, visualising and 
analysing energy data. Drawing on a feed from a smart meter, this device plots energy use along a temporal axis. ${ }^{3}$ The result is a real-time graph, which is marked up by users, noting things like toasters being switched on and off, the fact that it is Friday night, and the presence of teenagers in the house (See figure 1). Such a device thus highlights continuities between the social and the technical in ways that are not dissimilar to those outlined by sociologists.

We can, then, make an analogy between an argument from the social studies of technology and a technical operation enabled by the smart meter. To drive this point home, we might say that an application like the smart energy detective performs a conceptual operation advocated by social analysts of technology in the past: that of 'expanding the frame' on technology. The anthropologist of technology Lucy Suchman has characterized the social studies of technology as committed to this operation: in her account, social studies advocate a move away from a restrictive focus on technology as the principal agent of innovation, and an expansion of frames of analysis to foreground sociotechnical processes of "the ongoing, collective practices of sociomaterial configuration, and reconfiguration in use' (Suchman, 2005: 12). Suchman's account entails a topological imagination of society and technology, as the concept of sociomaterial reconfiguration gives pride of place to heterogeneous objects that stand in dynamic relations to one another. Not dissimilarly, the aforementioned proto-topological thinker Alfred Schutz also insisted on the importance of 'frame expansion' in relation to society and technology. In his famous essay on the 'WellInformed Citizen' (1964), he defined the role of the citizen in a technological society in terms of the task of 'expanding the frame.' In these societies, Schutz argued, the invention of new technologies of transport, energy and communication

\footnotetext{
${ }^{3} \mathrm{http} / / /$ www.energycircle.com/ted_display.php
} 
renders social life more complex and expands the times and spaces in which social life unfolds. To deal with this situation everyday subjects must learn how to 'reduce, as much as possible, the zone of the irrelevant' (Schutz, 1964).

One could then say that digital energy technologies are currently being configured as devices of frame expansion. In some ways, though only in some, graphs like that produced by the Energy Detective could be said to 'expand the frame' on energy use. They broaden the range of entities considered relevant to energy use beyond the 'strictly technical,' as they include elements such as teenagers in the equation of energy use, and situate them on the same plane as technical elements like toasters. And the broadening of the frame here too translates into a focus on processes in which social and technical entities are variously caught up. As digital devices allow the monitoring and analysis of energy-in-use, they make it possible to render energy demand as a dynamic practice, in which an array of heterogeneous - at least at first sight - entities are implicated. To some degree, then, smart energy meters can be said to enable the very topological imagination that has been singled out by social thinkers as what our current technological condition requires. Indeed, they can be said to enact what the sociologist Helga Nowotny (2002) refers to as the 'expansive present,' a term she proposes for the space-time that in her view is characteristic of the 'post-environmental' phase we are in today. Here, taking the environment into account no longer takes the form of a colonization of the future, onto which scenarios of environmental disaster and/or utopia are projected. Rather, it now operates through a maximization of the entities to be taken into consideration in the expansive present of social action: species, communities, lifestyles, and so on.

Nevertheless while current imaginations of everyday energy technology bear some similarities to sociological ideas about the mutual imbrication of the social and the technical, we should also note the ways in which they do not, in 
fact, 'expand the frame' on technology at all. Smart energy meters may be presented, in advertising and other publicity materials, as means to broaden the range of entities considered relevant to energy use, but they do so in ways that are very limited.

It has been observed that the spread of ideas of from cybernetics throughout societal discourses, in the 1990s and 2000s, has resulted in their weakening (Boltanksi and Chiapello, 2005; Brown, 2004). We can observe this in relation to the devices that 'expand the frame' on energy use, on at least two specific points. Firstly, while these devices invoke topological ideas to approximate the social and the technical, they tend not to conceive of the social in topological terms. An especially clear instance of this asymmetry can be found in Teatime Britain, a BBC-commissioned video that places us in the control room of the manager of the British Grid, at the end of Coronation Street. The end of this popular TV soap is followed by a surge in kettle-boiling across Britain, requiring the manager to make an intervention, and to bring online a French hydraulic dam at the last minute. On the one hand, such a vignette renders energy as a dynamic socio-technical process - as unfolding in a space-time of flexibility, liveness, and responsiveness. On the other hand, the social here figures as a scale-able national phenomenon (households in front of their TVs) that is neatly reducible to the technical (surge).

As in the IBM ad above, society is here defined in solidly scalar terms, a tiered system with individual consumers at one end and the national system at the other. This imagination of society is distinctly un-topological: a key feature of the topological conception of society in the sociology of technology has precisely been the idea that social arrangements do not fit the classic scalar space, which is associated with Euclidean geometry. That is, in a topological society, the nation is not necessarily bigger or stronger than, say, an electricity meter, and the domestic 
is not necessarily situated at a lower level than a map of the world. By contrast, devices like the Energy Detective continue to define the social in scalar terms. While it evokes a hybrid ontology involving both teenagers and toasters, the entities it posits all fit neatly into the envelope of 'domestic life.' The device, then, only 'expands the frame' to include relatively 'safe' micro-entities like teenagers, and not more complicated entities like 'carbon markets' or 'peak oil'. This suggests a more general point about current deployments of topology as a device for defining technology in social terms: even as the idea of dynamic space-time is used to bring into view the social dimension of technology, society itself continues to be defined in its 'Euclidean' capacity of a scalar arrangement composed of distinct levels of the micro, meso and macro, which together form a neatly organised whole or 'total space.'

There is also a second and perhaps even more important problem with 'topological devices' like the Energy Detective: a device like this does not enable a non-deterministic understanding of the relations between technological and social change. One could say that the Energy Detective, in rendering the social topologically, nevertheless still presents social entities in the role of what Harvey Molotch has persuasively called 'just another $\mathrm{f}^{* * *}$ dependent variable'. Energy technology continues to figure as the principal source of innovation, as something that enables the social but is in no way reducible to it. Even as the topological notion of complexity is used to bring society, technology and the environment together in a platform for energy use, the idea of technological innovation as the principal driver of change remains in place. This topological device does not challenge the 'primacy of technology'.

In this respect, one could say that the devices of frame expansion discussed so far deviate from the concept of frame expansion insofar as they still contribute to a 'seeing double'. On the one hand, these devices render everyday practices in 
topological terms, as they highlight the on-going reconfiguration of 'heterogeneous assemblages' involving toasters and teenagers. On the other hand, these devices do not extend the topological imagination to social entities themselves, which continue to be framed in scalar terms, and neither do they apply it to the relation between technological and social change, which continues to be defined as a causal one, however minimally speaking. These devices, one could say, welcome complexity within the frame of technological systems, but not as a complication of the frame, as the 'roll-out' of a technological system remains the critical operator of social change.

One response to this situation is to insist on the radical nature of topological theories of society and technology, as opposed to these devices. But I would instead like to explore further the idea that digital devices offer ways to "expand the frame' on technology. There may be different ways to configure digital technologies as topological devices of sorts, even so as to render technology social. To the 'weak' topology of a digital application like Energy Detective, we may be able to oppose 'stronger' topologies afforded by other kinds of devices. In other words, the proliferation of topological machines in digital culture does not only or necessarily entail the watering down of the sociological idea of the mutual entanglement of the social and the technical, but may also enable us to elaborate it further

\section{Mapping controversies: smart meters as problematic objects}

In order to challenge the 'weak' use of topology described above, in which complexity is only welcomed within the technological frame, we could start by recognising that digital energy technologies are also objects of frame expansion. ${ }^{4}$

\footnotetext{
${ }^{4}$ It is tempting to make an analogy here with the 'doubling of man' that is thematized in transcendental philosophy from Kant to Foucault (Rouse, 1994). According to this concept, it is distinctive of humans to
} 
That is to say, digital energy technologies do not only count as devices for expanding the frame on energy practices, they also figure as objects of such operations, insofar as they have become the object of public controversy. Devices like smart electricity meters, in recent years, have become the focus of a whole array of advocacy, research, and lobbying activities, in industrial, policy, scientific, non-governmental and creative circles (Darby, 2010; see also Michael and Gaver, 2009). These activities, too, can be said to involve attempts to 'expand the frame' on technology: scientific and political engagements with electricity metering, too, aim to broaden the range of entities to be taken into account in relation to energy: they seek to demonstrate the relevance of concerns ranging from fuel poverty to the presence of graphic displays on domestic meters (Preston and White, 2010).

Work in actor-network theory has long argued that, from a topological perspective on technology, controversies about technology are especially important. This work has proposed that controversies make possible frame expansions on technology too, not unlike those advocated by sociologists themselves. ${ }^{5}$ Controversy, it is argued, offers an occasion on which it is possible to establish the relevance of many more entities in relation to a particular technology than is otherwise possible (Latour, 2001; Barry, 2002; Callon et al, 2001; Fraser, 2007; see also Marres, 2007). ${ }^{6}$ That is, when technologies become issues, where

be both the subject and object of reflection all at once, and the idea can perhaps be applied to technology as well. .

${ }^{5}$ Of course, controversies about science and technology have long been recognized as a useful site for complicating prevalent understandings of the relations between the social and the technical (Bloor, 1982; Latour, 1987; Collins \& Pinch, 1998). In these events, public definitions of technology become destabilized, and this makes it much less likely to be cast in the role of the 'independent variable,' discussed above.

${ }^{6}$ This notion of controversy as frame expansion was first proposed by Michel Callon in the 1980s. He foregrounded problematization as a central dynamic of scientific discovery and innovation, which in his account is the consequence of the imposition of a new frame on the situation, and as a consequence of this, the opening up of the definition of the situation and the terms mobilized in relation to it (Callon, 1980). Notions of framing themselves have a much longer history, going back at least to Goffmann, Schutz and Dewey, and further to phenomenological and (neo-)Kantian traditions. 
matters of fact are transformed into matters of concern, the number of concerns that must be taken into account are radically broadened. And such an understanding of public controversy entails a topological imagination of society and technology in at least two ways. Firstly, a focus on the transformation of objects into issues entails a dynamic understanding of objects, suggesting that things may enter into quite radically different states when they become subject to controversy, or processes of 'issuefication' (Marres and Rogers, 2005). Secondly, such an approach highlights the interrelatedness of different orders: where objects turn into issues, scientific, moral and social concerns turn out to be intimately related and entangled (Latour, 2001). Public controversies thus evince a dynamic of 'frame expansion' too.iWhen we consider how public controversies unfold on digital platforms, we get into view a particular version of this topological dynamic, one that may offer a stronger alternative to the 'weak' topologies discussed above.

Before elaborating this point, however, I want to establish the difference between topological and 'Euclidean' understandings of public controversy, and the spaces and times in which they unfold, so as to clarify what is at stake in the adoption of a topological approach. A Euclidean perspective on controversy can be recognized in accounts that model controversy on 'public debate'. Such accounts tend to project an abstract debate space onto the issue under consideration, and then seek to position different actors in this space, to indicate their various perspectives or 'viewpoints' on the issue (Mol, 2002). Such an imagination of public controversy assumes that the space of controversy is analytically distinct from the controversy itself. One could say that a Euclidian imagination of controversy lifts social actors into an ideal space of public debate, in which actors are expected to settle into a single position that is true to their viewpoint, but this position-taking is not assumed to affect the shape of the space of debate itself. To give an empirical example, traces of such an approach can be 
recognized in an account of previous controversies about smart electricity meters in the 1990s by Marvin et al (1999):

A context needs to be created in which utilities, manufacturers and communications companies can be supplemented with the missing voices of regulators and user groups, such as environmental and community organisations.

In accounts like this, the principal aim of controversy is the establishment of a space in which different actors' views ('missing voices') can be included in the domestication of new technology. Controversy here makes possible the explication of actors' perspectives, so that a more inclusive definition of the object may result.

A topological ontology of public controversy differs from the Euclidean one on a number of points. As the former defines controversy in terms of the transformation of objects into issues, it enables a much more dynamic understanding of the spaces and times of controversies. A topological imagination of controversy, that is, recognizes the capacity of controversy to produce variations in the spaces and times of issues. And rather than defining controversy in terms of actors taking positions, it entails the unfolding of heterogeneous - social, technological, environmental, political, economic concerns. Digital devices, I want to argue, have the capacity to enable this kind of topological rendering of the space of controversy; that is, in relation to the stronger type of 'frame expansion' on technology afforded by controversy, topology offers a device, and not just a theory, for imagining the relation between technology and society differently.

This becomes clear if we consider the use of digital tools for the analysis and visualisation of public controversy. Online applications for data analysis and 
visualisation, that is, enable dynamic, and arguably 'topological' renderings of controversy (November and Latour, 2010; Scharnhorst and Wouters, 2006). However, what makes matters especially complicated here is that these applications have built into them particular methods of analysis and visualisation, on which social studies of technology has also relied in the past to analyze controversies. To speak of the deployment of topology as a device, in this case, is then to do more than suggest an analogy between a sociological concept and digital technologies. It is to highlight that certain methods of 'topological' analysis have become built into digital technologies in recent times.

Sociologists of technology have long relied on methods of network and textual analysis in order to capture the unfolding of controversies in ways that we can call 'topological' (Callon et al, 1983; Leydersdorff, 1996). In order to map the 'frame expansions' on technology occurring in controversies, they produced visualisations of the unfolding relations between heterogeneous actors and terms caught up in public controversy. Today the proliferation of digital technologies means that similar methods are deployed much more widely to analyse and visualise issues in digital networked media (Rogers and Marres, 2000). Indeed, network and textual analysis tools are now routinely deployed in digital culture, in the form of search engines that rely on hyperlink analysis to capture evolving relevance relations (Google), and of blogs that use clouding software to disclose 'dynamic content' (Worldle) (Van Couvering, 2007; Rogers, 2009, see also Marres, 2012). And this proliferation of network and textual analysis across social life in the guise of 'digital methods' has consequences for the social analysis of public controversy. Here too, we can note a change in status of the topological analysis of technology and society.

In classic controversy analyses in the social studies of science and technology a topological conception of public controversy had analytic status: the 
concept of heterogeneous assemblages unfolding in a dynamic space-time was projected onto empirical material by virtue of the methods and concepts deployed in social studies of public controversies about technology. By contrast, in the context of digital culture, the topological configuration of controversy spaces can be approached as an empirical effect. This is partly the consequence of the deployment of 'topological devices' of network and textual analysis across digital culture. $^{7}$ An example of this type of topological rendering of public controversy, produced with the aid of a tool of Web analysis, can help to make this clear.

\begin{tabular}{|c|c|}
\hline \multirow[b]{2}{*}{ tagcloud48-19-19-11-09 } & 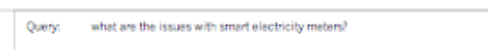 \\
\hline & Digital Methods Initiative 19 Nonenter 09 \\
\hline \multicolumn{2}{|r|}{ 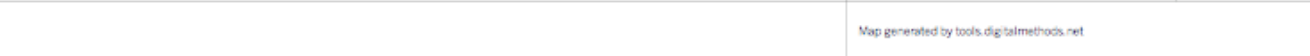 } \\
\hline \multicolumn{2}{|c|}{ Accountability(1) COSt (7) Dyramic demand management(1) Distrobutonal etects (1) Efficiency (5) Flexibility (2) } \\
\hline \multicolumn{2}{|c|}{ 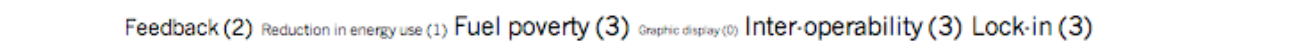 } \\
\hline \multicolumn{2}{|c|}{$\begin{array}{l}\text { Privacy (7) Remote switching (2) Security of supply (2) Spy in the home (2) } \\
\text { Smart grid (9) Surveillance (5) }\end{array}$} \\
\hline
\end{tabular}

\footnotetext{
${ }^{7}$ This is one of the focal points of the recently concluded collaborative EU-project Mapping Controversies (MACOSPOL) initiated by Bruno Latour, together with Kristin Asdal, Massimiano Bucchi, Cordula Cropp, Dominique Lindhardt, François Mélard, Valerie November, Richard Rogers, Albena Yaneva, Andre Mogoutov and others, including myself. http://www.mappingcontroversies.net
} 
Figure 2: Tag cloud, frequencies of terms in a UK controversy about smart electricity meter according to the Googlescraper, November 2009

Figure 2 presents the result of a Web-based textual analysis of a recent public controversy about smart energy meters in the UK. The controversy in question flared up in the fall of 2009, after the publication by the Department of Energy and Climate Change (DECC) of its impact assessment of "smart metering of gas and electricity in the domestic sector." In the week following the publication of this report, a range of news stories raised concerns, as the consumer organisation Consumer Focus suggested that smart meters could be used by utility companies to switch off non-paying customers. ${ }^{8}$ Smart meters, these stories also suggested, could provide a channel for third party services, consumer applications that would run on top of smart meters, and as such would serve as what The Daily Telegraph called a "spy in the home". ${ }^{9}$ In order to find out whether these issues were the subject of a wider controversy, I used a web-based tool called the Googlescraper, which piggy-backs on Google to determine whether terms have resonance on selected Web pages. ${ }^{10}$ Querying a set of Web pages of NGO's blogs, company and news sites, which link to the DECC Impact assessment, I found the distribution of terms illustrated in Figure 2. Such an 'issue cloud' visualisation can help to specify the type of 'frame expansion' on technology that is enabled by digital devices. The figure shows a range of concerns that became associated with smart meters on the occasion of DECC's impact assessment report, or perhaps one could say, it provides an indication of the 'controversiality' of smart energy meters in a particular time and space, namely that opened up by this report.

\footnotetext{
${ }^{8}$ Consumer Focus, "Reduce risks and increase benefits of smart meters," press release, London, September 30, 2009

9 Alastair Jamieson, Smart meters could be 'spy in the home", Daily Telegraph, 11 October, 2009

${ }^{10}$ The Googlescraper was designed by the Digital Methods group in Amsterdam.
} 
Such a rendering itself can be accounted for in several ways. Thus, we may approach Web pages as representing actor positions, and understand the weighing of terms going on here in terms of actors putting their weight behind certain issues and not others. As Bruno Latour and Richard Rogers have also argued, Web analysis offers a way to take up an idea of the $20^{\text {th }}$ Century American journalist Walter Lippmann, that 'actor partisanship' provides an effective measure for clarifying complex processes of issue formation (Latour, 2008; Rogers and Marres, 2002). But there is also another way of reading the issue cloud, one that plays up the difference that a topological rendering of controversy can make to our conception of controversy. As the Figure provides indications of the scope of terms that are currently active in the controversy on smart electricity meters, it can be taken as disclosing the "state of issuefication" of the object called smart meter. Here controversy involves not so much actors taking positions, but a process of the problematization of objects, by which they become charged with various social, economic, political problematics or issues. ${ }^{11}$

An analysis of public controversy as a process of 'issuefication' can be distinguished from the other perspectives on public controversies about technology outlined above, and has implications for how we define 'expansions of the frame' on technology. Firstly, online issue mapping can be distinguished from approaches that define controversy in terms of public debate. Deploying a digital research tool like the Googlescraper, controversy analysis is not so much a matter of determining once and for all the positions of actors and their inclusion in, or exclusion from, debate spaces. Rather, it becomes a way of finding out about the

\footnotetext{
${ }^{11}$ Problematization is a concept adopted by Foucault and later in actor-network theory, and can be traced back to the pragmatist concept of the problematic situation. But these approaches fill in the concept slightly differently: in Foucault problematization figures as an attribute of discursive regimes (Rabinow, 2005) while in ANT and pragmatism problematization figures as an event: one could say that here it refers not so much to an epistemic effect as to an ontological moment. However, while Callon adopted the pragmatist notion of problematization in the study of innovation processes, he arguably opted for an epistemic rather than an ontological version of it.
} 
dynamic composition of objects in terms of issues or actors in information spaces that are always in flux. Which is to say, to analyse processes of issuefication with the aid of digital devices is to adopt an explicitly topological approach to public controversy.

Just as in the case of the framing of smart meters as 'social technologies' discussed in section 2, a focus on public debate typically involves a form of 'seeing double', but from the opposite direction: here, the social, cultural and political processes of framing technology are affirmed, but the role of technology in organising such processes of frame expansion is not really considered. That is, while such approaches recognize that technology may serve as an object of frame expansion, they do not acknowledge the role of technology as a device of frame expansion. As the abstract form of public debate is projected onto a given issue area, it becomes difficult to appreciate how spaces of issues are themselves organised by technological means. The space of controversy is here delineated by purely analytic means. By contrast, to analyse processes issuefication with the aid of a topological device like a tag cloud visualisation, makes it possible to examine the empirical unfolding of the space-times of issues. The topological unfolding of a space-time of controversy is revealed to be partly an artefact of the devices used to render controversy visible and analysable. The topological organisation of controversy, that is, is here accomplished experimentally, through the deployment of digital devices. And this, in turn, has implications for how we imagine the relation between social and technological change.

\section{Expanding the frame on socio-technical change}

In the above analysis of an object controversy, using a topological device does not only help us to appreciate the entanglement of the social and the technical in said object, but also brings into view the empirical unfolding of the object qua issue. 
This has implications for the long-standing debate flagged in the introduction, that about the relation between technological and social change, and how topology may contribute to our understanding of it. It disrupts a frequently made criticism of topological approaches to technology and society. Such approaches have been criticized for making it difficult to generalize meaningfully about societal and technological change. A topological imagination of technology and society has been said to come at a price: it reframes change as something internal to sociotechnical collectives. And if socio-technical change is located inside 'ongoing, collective practices of reconfiguration,' as Lucy Suchmann (2005) has put it, then processes of change are likely to be rendered complex to the point of becoming impossible to summarize. A topological rendering of controversy, as discussed above, can be said to offer a way of dealing with this risk of dissolving change into the minutiae of on-going practice insofar as it is able to bring into view a range of proliferating, contending articulations of socio-technical change.

The distribution of controversy terms across Web pages dealing with smart meters in the UK ascribes to these objects different possible normative effects, in terms of privacy, surveillance, fuel poverty, remote disconnection, and so on. To be sure,he co-occurrence of these issue terms does not necessarily add up to any coherent picture of a changing world: smart meters may provide opportunities for the monitoring of consumer behaviour; and they are also critical to the making of a low-carbon economy and thereby to addressing the global environmental threat of climate change; and they are also likely to have 'distributional effects' that contribute to socio-economic inequality. ${ }^{12}$ A cloud of such issues, that is, does not quite offer a generalization, but it does provide a screenshot of the distribution of

\footnotetext{
${ }^{12}$ Max Hogg "Do smart meters actually save energy?", Financial Times, May 11, 2009
} 
types of socio-technological change, and thus gives a sense of the work of projection involved in the enactment of socio-technical change.

For this reason, issue analysis cannot quite be said to render socio-technical change internal to socio-material practices. Yes: in exploring the issuefication of smart electricity meters, the question of socio-technological change is complexified, as it forces a recognition of the proliferation of diverging articulations of change. But: processes of change are not rendered so complex that it is no longer meaningful to envision more broad-stroked changes of sociotechnical arrangements. ${ }^{13}$ This does not put us in a comfortable situation. In a public controversy like that around smart energy meters, a range of issue terms are rendered relevant to this technology, but there is no assurance that these issues will ever cohere, if by that is meant that they might become mutually relevant. It is not self-evident that the issue terms necessarily add up to a single something. We might say that while problematizations of smart meters are abundant, these problematizations are not necessarily expansive. ${ }^{14}$ These issues do not as a matter of course translate into anything that might deserve the name of a 'topology of relevance', in a variation on the aforementioned 'cartographies of relevance' invoked by Alfred Schutz. Issue mapping may easily end up disclosing noncontroversies. ${ }^{15}$ Online issue analysis, then, sensitizes us to the ways in which

\footnotetext{
${ }^{13}$ Relative non-coherence also implies relative under-determinacy: as Sarah Darby (2008) concluded on a different basis: "smart metering cannot be specified satisfactorily from any single standpoint, there are too many questions from too many directions."

${ }^{14}$ A similar point has been made by Annemarie Mol (2002), in her critique of controversy studies, namely that these studies do not sufficiently recognize the spatio-temporal distribution of science and technology. However, Mol's critique relies heavility on an ethnographic apprehension of topological distribution, and as such it risks what might be called a 'methodological exceptionalism': it suggests that only with the aid of special methods of ethnography can we access topologies of irrelevance, suggesting that this frame expansion is the exclusive privilege of social studies.

${ }^{15}$ To give an empirical indication of this: the 2009 controversy about smart meters spawned by the DECC impact assessment did not translate into a coherent 'issue network', at least not on the Web. The organisations, individuals and media outlets that reported critically on the outcome of its impact assessment, aren't in actuality organised in a problem-specific configuration: their Web sites disclose only a very loosely connected network consisting of UK government and regulatory agencies, the UN climate agency IPPC, and one book called Hot Air.
} 
problematizations are abundant without being expansive, and invites us to take this seriously as a condition of social, technological and environmental change.

\section{Conclusion}

Digital devices enable a topological analysis of technology and society in a variety of ways. They make it possible to broaden the range of entities to be taken into account in relation to technology, and they do this with varying implications. In some cases, frame expansions result in a celebration of the entanglement of society and technology, highlighting the ways in which technologies are 'alive' with sociality. In other cases, topological renderings of technology demonstrate the multiplicity of issues opened up by that technology. That these different topological approaches to technology and society are increasingly prevalent places special requirements on the social studies of technology. In this context, it becomes less important to advocate a topological understanding of technology and society, as opposed to a non-topological one. Rather, we must now examine how topological devices are variously deployed to render social technology, and focus on discerning subtle but decisive differences between these various deployments. One could say that it now becomes our task, as social analysts of technology, to be demanding of topological analyses of technology and society. It is not enough to point at the great opportunities for a social analysis of complex dynamics that are enabled by the proliferation of digital technologies across society. It is not enough to affirm the mutual imbrication of technological and social arrangements, if this leaves in place assumptions about the neat alignment of technological and social change. Rather, we must demonstrate that a stronger form of topological analysis is called for, and provide pointers as to how this might be developed.

To this end, I have distinguished two ways of analysing technology and society topologically, two ways of 'expanding the frame' on technology. A first 
type of frame expansion focuses on technology-in-use, and is enabled by technologies like smart energy meters. Here, frame expansion helps to highlight proliferating connections between social and technological entities within a technologically delineated space, say that of energy-in-use. A second type of frame expansion is concerned with societal processes of the problematization of technology, which digital devices of issue analysis and visualisation can help to bring into view. In this case, the deployment of a topological device helps to bring into view dynamics of the 'issuefication' of technology, the unfolding of concerns in an empirical space-time of publicity. Where in the first case frame expansion results in the inclusion of more entities in the technological frame, in the second case it results in the problematization of technology. And this difference matters insofar as it translates into a different analysis of the relations between technological and social change.

In the first case, a topological analysis of society and technology provides a way of recognizing the mutual imbrication of technology and society, but it does not affect assumptions about the primacy of technological over social change, or challenge the view that the former can stand in for the latter. In the second case, a topological analysis does translate into an different imagination of the relations between technological and social change: topological analysis here brings into view the proliferation of contending articulations of techno-social change, and, thus, a situation in which different forms and types of change are made visible although they cannot be assumed to be neatly aligned. As frames are expanded on technology, and more and more entities prove to be implicated, socio-technical dynamics turn out to be much less coherent than expected.

In a situation in which topological devices are widely deployed to analyse and organise technology, linear, causal understandings of technology and society should perhaps cease to be the main focus of critique. Controversy analysis may 
point a way forward in this respect, in that it offers a way of performing critique by empirical means. Mapping controversies brings into view social processes of the problematization of technology, and as such, it depicts technology in a 'critical state,' so to speak. However, crucial to the topological rendering of controversy, is that 'problematization' here takes the form of an empirical unfolding: problem-spaces and times, it here become clear, are organised through empirically traceable key-words, hyperlinks and so on. ${ }^{16}$ For this reason, mapping controversies may be said to offer a way of being critical that does not require a transcendentalizing move. , To develop such empirical forms of critique requires more serious work and reflection on the tools and methods of topological analysis, and in particular, on the kinds of ontologies that get built into the software applications on which we rely. Here I have only flagged the broad difference between an ontology that focuses on the inclusion of heterogeneous entities, versus an ontology which foregrounds processes of issuefication. .

Finally, there is an important question of the imagination that needs addressing, which is the question of whether and how a normative social science can handle the relative non-coherence of dynamic objects (Law, 2004). A demanding or critical mode of analysis has long been associated with paranoia, that is, with the risk of assuming coherence where there is none (Dean, 2000). The question raised here is whether social science can handle a risk of almost the opposite kind: is it possible to recognize the relative non-coherence of societal and technological processes, and still be demanding of them? We may reject easy assumptions of the alignment of social and technological change, but are we really capable of acknowledging the mis-alignment of different forms of change, and still formulate intelligent demands for change? The question seems especially urgent in the context of proliferating digital technologies, in which the complexity

\footnotetext{
${ }^{16}$ This contrast with the status of ontological incoherence in 'post-ANT,' where it tends to be presented as a sub-discursive phenomenon, as a metaphysical pattern that tends to escape mainstream empirical analysis.
} 
of change, the modification of collectives along multiple axes, and the ways in which change actually does not add up or point in one direction (for example, democratizing energy $=$ increasing surveillance), are rendered legible in publicity media. Can we analyse change as not necessarily coherent, and still be demanding of it?

\section{References}

Barry, Andrew (2001) Sights and Sites. In: Political Machines: Governing the Technological Society. London: Athlone Press.

Berker, Thomas (2005) Smart machines and dubious delegates: The representation of user agency in the design of energy efficient buildings. STS working paper, Norwegian University of Science and Technology, Trondheim.

Bloor, David (1982) Durkheim and Mauss Revisited: Classification and the Sociology of Knowledge. Studies in History and Philosophy of Science 13 (4):267-97.

Boltanksi, Luc and Eve Chiapello (2005) The New Spirit of Capitalism. London/New York: Verso.

Brown, Steven (2004) As If Bergson Had an MBA. Paper presented at the international workshop Does STS Mean Business? Oxford Said Business School, 30 June.

Callon, Michel, Pierre Lascoumes \& Yannick Barthe (2001) Agir dans un monde incertain. Essai sur la démocratie technique. Paris: Seuil.

Callon, Michel, John Law and Arie Rip (Eds.) (1986) Mapping the Dynamics of Science and Technology. London: Macmillan.

Callon, M. (1986). Some Elements of a Sociology of Translation: Domestication of the Scallops and the Fishermen of St Brieuc Bay. In John Law (ed.), Power, Action and Belief: A New Sociology of Knowledge. London: Routledge \& Kegan Paul

Callon, Michel and Jean-Pierre Courtial, William A. Turner and Serge Bauin (1983) From translations to problematic networks: An introduction to co-word 
analysis. Social Science Information 22 (2): 191-235.

Callon, Michel (1980). Struggles and Negotiations to define what is Problematic and what is not: the Sociology of Translation. In K. D. Knorr, R. Krohn and R. D. Whitley (Eds.) The Social Process of Scientific Investigation: Sociology of the Sciences Yearbook. Dordrecht and Boston, Mass., Reidel. 4: 197-219.

Collins, Harry and Trevor Pinch (1998) The Golem: What everyone should know about science. Cambridge: Cambridge University Press.

Darby, Sarah (2010) Smart metering: what potential for householder engagement? Building Research and Information, 38(5): 442-457.

Darby, Sarah (2008) Why, what, when, how, where and who? Developing UK policy on metering, billing and energy display devices. In: Proceedings of ACEEE Summer Study on Energy Efficiency in Buildings, Asilomar, CA.

Dean, Jodi (2000) “Theorizing Conspiracy Theory," Theory and Event 4.3.

De Landa, Manuel (1991) War in the Age of Intelligent Machines. New York: Zone Books.

Dewey, John (1939 (1908)). Theory of valuation. Repr. In Otto Neurath, Rudolf Carnap, and Charles Morris (Eds.) International Encyclopedia of Unified Science, vol. 2, no. 4. Chicago: University of Chicago Press, 1955.

Edwards, Paul (2000) The World in a Machine: Origins and Impacts of Early Computerized Global Systems Models. In: Thomas P. Hughes and Agatha C. Hughes (Eds.) Systems, Experts, and Computers: The Systems Approach in Management and Engineering World War II and After. Cambridge, MA: MIT Press, pp 221-254.

Fraser, Mariam (2007) What Matters? Paper presented at the workshop Devices: The Happening Of The Social, Goldsmiths, University of London, December.

Fuller, Matthew (2007) Introduction. In Matthew Fuller (Ed) Software Studies, a lexicon. Cambridge MA: MIT Press.

Haraway. Donna (1994) A Game of Cat's Cradle: Science Studies, Feminist Studies, Cultural Studies. Configurations 2 (1): 59-71.

Kallinikos, Jannis (2011) Governing through technology: information artefacts and social practice. Basingstoke: Palgrave Macmillan. 
Latour, Bruno (2009). "Tarde's idea of quantification.” The Social After Gabriel

Tarde: Debates and Assessments. Ed. Mattei Candea. Routledge, London, pp. 145162

Latour, Bruno (2008) Introduction. In Walter Lippmann, Le Public fantôme. Paris: Demopolis.

Latour, B. (2001). From 'matters of facts' to 'states of affairs'. Which protocol for the new collective experiments?. Lecture to the Darmstadt Colloquium, $30^{\text {th }}$ March.

Latour, Bruno (1993) We have never been modern, Cambridge (MA): Harvard University Press.

Latour, Bruno (1988) A Relativistic Account of Einstein's Relativity. Social Studies of Science 18 (1): 3-44

Latour, Buno (1987). Science in Action: How to Follow Scientists and Engineers Through Society. Milton Keynes: Open University Press.

Law, John. (2004) After Method: Mess in Social Science Research. London and New York: Routledge.

Law, John and Annemarie Mol (2002) Complexities: social studies of knowledge practices. Durham, NC: Duke University Press.

Lazer, D. and A. Pentland, L. Adamic, S. Aral 2 , A. Barabási, D. Brewer, N. Christakis, N. Contractor, J. Fowler. M. Gutmann, T. Jebara, G. King, M. Macy, D. Roy, M. Van Alstyne (2009) Computational Social Science, Science, 6 February, 5915 (323): 721-723.

Leydesdorff, L. and H. Etzkowitz (1996) Emergence of a Triple Helix of University-Industry-Government Relations. Science and Public Policy 23: 279286.

Lury, Celia (2010) 'Devising the Social,' Keynote lecture at the CRESC conference The Social Life of Methods, St Hugh's College, Oxford, August 31September 3.

Marres, Noortje (2012) The Experiment in Living. In Celia Lury and Nina Wakeford (Eds) Inventive Methods: The Happening of The Social. London: Routledge. 
Marres, Noortje (2009) Testing Powers of Engagement: Green Living Experiments, the Ontological Turn and the Undoability of Involvement, European Journal of Social Theory 12 (1): 117-133.

Marres, Noortje (2007) The Issues Deserve More Credit, Pragmatist Contributions to the Study of Public Involvement in Controversy. Social Studies of Science 37 (5): 759-780.

Marvin, S. and H. Chappells, S. Guy (1999) Pathways of smart metering development: shaping environmental innovation. Computers, Environment and Urban Systems (23): 109-126.

Michael, Mike (2000). Reconnecting Culture, Technology and Nature: From Society to Heterogeneity. London: Routledge.

Michael, Mike and Bill Gaver (2009) Home Beyond Home: Dwelling With Threshold Devices. Space and Culture 3 (12): 359-370.

Mol, Annemarie (2002) The Body Multiple: ontology in medical practice. Durham: Duke University Press.

Mol, Annemarie, and John Law (1994) "Regions, Networks and Fluids: Anaemia and Social Topology." Social Studies of Science 24 (4): 641-671.

Muniesa, Fabian, A Flank Movement in the Understanding of Valuation. In Lisa Adkins, Roger Burrows and Celia Lury (Eds) 'Measure and Value' Special Issue for The Sociological Review, forthcoming.

November, Valerie and Bruno Latour (2010) Entering a risky territory: space in the age of digital navigation. Environment and Planning D: Society and Space (28): 581-599

Nowotny, Helga (2002) Vergangene Zukunft: Ein Blick zurück auf die 'Grenzen des Wachstums. in Impulse geben - Wissen stiften. 40 Jahre VolkswagenStiftung, VolkswagenStiftung: Göttingen, pp. 655-694.

Nowotny, Helga (1990) Actor-networks vs. science as self-organizing system: A comparative view of two constructivist approaches. Sociology of the Sciences 14: 223-239.

Nye, David (1999) Consuming Power: A Social History of American Energies, Cambridge: MIT Press. 
Preston I and V. White (2010) The Distributional Impacts of UK Climate Change Policies, Final report to the Eaga Charitable Trust, Centre for Sustainable Energy and Association for the Conservation of Energy.

Rabinow, Paul (2005). Midst Anthropology's Problems. In: Aihwa Ong and Stephen J. Collier (eds) Global Assemblages: Technology, Politics, and Ethics as Anthropological Problems. London and New York: Blackwell Publishing, pp $40-$ 58

Reed-Tsochas, Felix (2006) Tracking People's Electronic Footprints (10 November, Science 314: pp. 914-916.

Rogers, Richard (2009) The End of the Virtual. Amsterdam: Vossiuspers UvA.

Rogers, Richard and Noortje Marres (2002) French scandals on the Web, and on the streets: A small experiment in stretching the limits of reported reality. Asian Journal of Social Science 30 (2): 339-353.

Rouse, J. (1994) Power/Knowledge. In Gary Gutting (ed) The Cambridge Companion to Foucault. Cambridge: Cambridge University Press.

Scharnhorst, Andrea and Paul Wouters (2006) Web indicators - a new generation of S\&T indicators Cybermetrics, 10 (1).

Schutz, Alfred (1964) The well-informed citizen. In: Collected papers. Vol. II. Studies in social theory. The Hague: Martinus Nijhoff, pp. 120-134.

Schutz, Alfred (1970). Reflections on the Problem of Relevance. Richard Zaner (Ed). New Haven, CT: Yale University Press.

Star, S. L. (1991). Power, Technologies and the Phenomenology of Conventions: on being Allergic to Onions. In J. Law (Ed.) A Sociology of Monsters? Essays on Power, Technology and Domination, Sociological Review Monograph. London, Routledge. 38: 26-56.

Suchman, Lucy (2005) Agencies in Technology Design: Feminist Reconfigurations. Presented at the Workshop on Gendered Innovations in Science and Engineering, Stanford University, April 15-16, http://www.lancs.ac.uk/fass/sociology/papers/suchman-agenciestechnodesign.pdf

Van Couvering, E. (2007). Is relevance relevant? Market, science, and war: Discourses of search engine quality. Journal of Computer-Mediated 
Communication 12(3), article 6.

http://jcmc.indiana.edu/vol12/issue3/vancouvering.html

Woolgar, S. (1999). Do artefacts have ambivalence? - Moses' bridges, Winner's bridges and other urban legends. Social Studies of Science (29): 433-449. 